\title{
Development of Gallbladder Contractility in the Guinea Pig
}

\author{
CAROL M. DENEHY AND JAMES R. RYAN \\ Department of Physiology, Temple University School of Medicine, Philadelphia, Pennsylvania 19140
}

\begin{abstract}
In vitro experiments were performed to examine the contractile responsiveness of guinea pig gallbladder smooth muscle as a function of developmental age. Gallbladder muscle strips from preterm (day 50-55 gestation), newborn (days 1-3 post partum), and 1-month-old animals were stimulated with agonists that initiate the contractile process either by activation of membrane receptors (acetylcholine and the octapeptide of cholecystokinin) or by membrane depolarization (potassium). Dose-response curves were constructed for each agonist in each age group and analyzed with respect to the maximal force developed and the $\mathrm{pD}_{2}$ value (negative logarithm of the dose of agonist which produces a one-half maximal response). The results can be summarized as follows: 1) when normalized for tissue cross-sectional area, the magnitude of the contractile response to each agonist increased with increasing developmental age; 2 ) the dose of agonist required to elicit a one-half maximal response was independent of developmental age. The data indicate that cholinergic and cholecystokinin receptors are present and functional on gallbladder smooth muscle prior to birth and that the force generating capacity of the tissue continues to develop after birth. A reduced contractility of the gallbladder in preterm and newborn animals as compared to young adults may partially explain the decreased choledochol bile flow seen in the neonate. (Pediatr Res 20: 214-217, 1986)
\end{abstract}

\section{Abbreviations}

CCK-OP, octapeptide of cholecystokinin ACh, acetylcholine

Normal growth and development in the newborn is dependent on many processes. Ultimately, however, the ability of the infant to survive depends on its ability to digest and absorb nutrients (1-3). Fats comprise $50 \%$ or more of the milk calories in most animal species and thus are a major factor in infant nutrition (4). Fat digestion is a complex process requiring input from both the pancreas and the hepatobiliary system. In particular, bile salts are necessary to stabilize the pancreatic lipolytic enzymes and to solubilize the products of lipolysis into micelles. Both the bile salt pool size and the rate of bile-salt synthesis are reduced in infants as compared to adults. This apparent immaturity of the hepatobiliary system has been implicated in the decreased bile excretion, inefficient fat digestion, and propensity to cholestasis often observed in newborn infants (5-8).

In addition to the synthesis and secretion of hepatic bile, a

Received July 25, 1985; accepted October 24, 1985

Send all correspondence and requests for reprints to James P. Ryan, Ph.D., Deartment of Physiology, Temple University School of Medicine, Philadelphia, PA 19140.

This study was supported in part by NIH Grant HD16132. major factor which affects the intraluminal concentration of bile acids is the contractile ability of the gallbladder (9). The dynamics of gallbladder motility in the neonate has received little attention. Kaplan et al. (10) recently evaluated gallbladder mechanics in newborn piglets and reported a decreased intracholecystic pressure response to agonist stimulation, when compared to the adult. They speculated that the decreased pressure response reflects a decrease in smooth muscle contractility. The present study was designed to test this hypothesis by examining the in vitro contractile responsiveness of gallbladder muscle strips from newborn and adult guinea pigs. In addition, tissues from fetal animals were studied. This group was included in order to more fully define the development of gallbladder smooth muscle contractility.

\section{METHODS}

Animal model. The in vitro contractile responsiveness of the guinea pig gallbladder was studied using tissues obtained from fetuses, full term neonates, and young adults. Fifteen date-mated pregnant animals were obtained from a reliable breeder (Perfection Breeders, Douglassville, PA). Normal parturition occurred in nine of these animals. Thirteen pups were randomly selected to be studied as newborns. These animals were studied between 1 and 3 days of age and had a mean weight of $101.6 \pm 8.2 \mathrm{~g}$ and a crown-rump length of $15.2 \pm 1.2 \mathrm{~cm}$. The remaining animals $(n=12)$ which delivered spontaneously were housed with their mother for subsequent study as young adults (average age $=33.5$ \pm 2.1 days; mean weight $=380.2 \pm 33.1 \mathrm{~g}$ ). Sixteen 3 rd trimester fetuses (day 50-55) were delivered by ceasarian section from six pregnant animals. The normal gestation time in the guinea pig is 68-70 days. The fetuses had a mean weight of $69.8 \pm 1.4 \mathrm{~g}$ and a crown-rump length of $13.4 \pm 0.5 \mathrm{~cm}$

Tissue preparation. After induction of anesthesia (Ketamine $\mathrm{HCl}, 100 \mathrm{mg} / \mathrm{kg}$ ), gallbladders from newborns and young adults were removed through a midline incision. Gallbladders from fetal animals were obtained without the benefit of anesthesia. Once removed, the gallbladders were immediately placed in an agar lined petri dish filled with aerated, room temperature KrebsRinger solution (composition in $\mathrm{mM}: \mathrm{Na}^{+}, 138.6 ; \mathrm{K}^{+}, 4.6 ; \mathrm{Ca}^{2+}$, $2.5 ; \mathrm{Mg}^{2+}, 2.1 ; \mathrm{Cl}^{-}, 126.2 ; \mathrm{HCO}_{3}{ }^{-}, 21.9 ; \mathrm{PO}_{4}{ }^{-}, 1.2$, and glucose 12.7). Each gallbladder was opened along the longitudinal axis, anchored open with fine pins, and the mucosa removed by blunt dissection. A single muscle strip $(3 \times 7 \mathrm{~mm})$ was obtained from the body of each gallbladder by cutting parallel to the circular axis. One end of each muscle strip was connected via plastic clip and gold chain to a force transducer (Grass FT03C) and the other end attached to a metal rod that could be raised or lowered by the adjustment of a screw micrometer. The muscle strips were then transferred to individual $20 \mathrm{ml}$ tissue chambers (PhippsBaird) which were filled with warmed $\left(37^{\circ}\right)$, aerated $\left(95 \% \mathrm{O}_{2}\right.$, $5 \% \mathrm{CO}_{2}$ ) buffer solution.

The muscle strips were allowed to equilibrate without any applied tension for one hour. After that time, the length of each 
muscle strip was increased in 2-mm increments until the maximal active contractile response to acetylcholine $\left(10^{-5} \mathrm{M}\right) \mathrm{stimu}$ lation was achieved (11). The muscle length corresponding to the optimal preload was maintained throughout the duration of the experiment.

Muscle stimulation. The muscle strips were examined for their contractile responsiveness to ACh (Sigma), CCK-OP (Sincalaide), and elevated levels of extracellular potassium. Stock solutions of $\mathrm{ACh}$ and $\mathrm{CCK}-\mathrm{OP}$ were prepared and added fresh daily to the tissue baths in microliter amounts to achieve the final molar conconcentrations reported. Individual doses were given in random order; no cumulative dose-response curves were constructed. When the contractile response to elevated extracellular potassium was evaluated, the $\mathrm{NaCl}$ concentration of the bathing medium was reduced accordingly in order to maintain osmolality. In general, complete dose-response curves could be obtained for any two agonists on any one muscle strip. Permanent records of the isometric tensions developed were attained using a Grass (7P1) multichannel recorder.

Data analysis. Upon completion of each experiment, the muscle strip length at optimal preload was measured using a calibrated eyepiece micrometer and the muscle weight determined. The individual contractile responses were then normalized for tissue cross-sectional area (11). Cross-sectional area was calculated according to the following relationship: area = mass/ (density $\times$ length), where mass is in grams, the length in centimeters, and the density is assumed to be $1.05 \mathrm{~g} / \mathrm{cm}^{3}$ (12). The dose-response curves for each agonist in each age group were analyzed for the maximal contractile response and the $\mathrm{pD}_{2}$ value, defined as the negative logarithm of the dose of agonist which causes a one-half maximal response (15). The significance of the data was determined by analysis of variance followed by the Student's $t$ test for unpaired observations. Statistical significance was established at the $95 \%$ confidence limit. All results are expressed as the mean \pm SEM.

\section{RESULTS}

Basal activity. The resting tension at which maximal active force development occurred was $0.75 \pm 0.12 \mathrm{~g}$ for fetal tissues $(n$ $=16), 1.0 \pm 0.12 \mathrm{~g}$ for tissues from newborn guinea pigs $(n=$ $13)$, and $1.15 \pm 0.25 \mathrm{~g}$ for tissues from young adults $(n=12)$. The values do not differ significantly from one another. In previous studies it has been shown that gallbladder muscle strips from adult guinea pigs $(500-700 \mathrm{~g})$ contract spontaneously at a frequency of $4-5 / \mathrm{min}$ when studied in vitro (11). In the present study muscle strips obtained from young adults (mean weight, $380 \mathrm{~g}$ ) exhibited a similar contractile behavior. Spontaneous contractions were evident in all tissues and lasted for the duration of the experiment. In contrast, tissues from newborn animals exhibited an erratic spontaneous contractile pattern. While the contractions lasted for the duration of the experiment, both the frequency and magnitude varied during the course of the experiment. Tissues from preterm animals only infrequently exhibited any spontaneous phasic contractile activity. When present, both the frequency and the amplitude were erratic and did not last the entire experimental day.

Responses to agonists. All of the muscle strips examined were responsive to each of the agonists tested. The dose-response relationship of tissues from fetal, newborn, and young adult guinea pigs to stimulation with $\mathrm{ACh}$ is shown in Figure 1. Within each age group increasing the concentration of agonist was associated with an increased force of contraction. The maximal tension developed in each age group is given in Table 1. Tissues from newborn animals contracted with significantly more force than tissues from fetal animals; tissues from young adults evidenced contractions which were significantly greater than the force developed in either of the other two groups. Although the magnitude of the contractile response to ACh varied with devel-

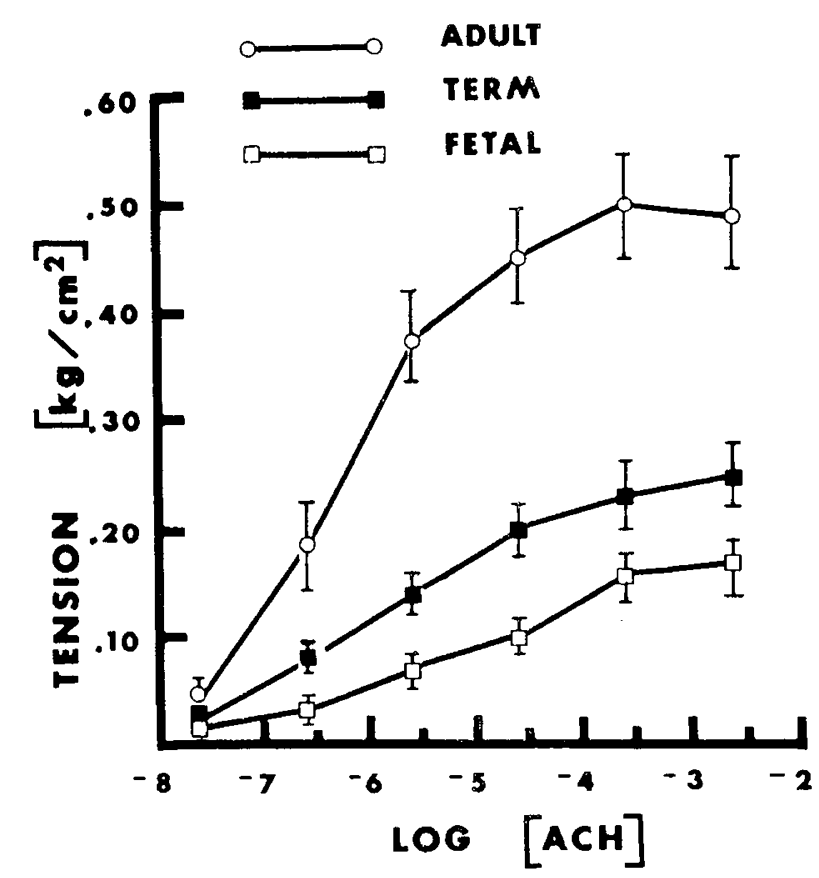

Fig. 1. Dose-response curve for $\mathrm{ACh}$ in isolated gallbladder smooth muscle strips from fetal, newborn, and young adult guinea pigs. Each point represents the mean \pm SEM of at least 12 determinations.

Table 1. Maximal tension development in isolated gallbladder muscle strips from fetal, newborn, and young adult guinea pigs $($ mean $\pm S E M)$

\begin{tabular}{lccc}
\hline & \multicolumn{3}{c}{ Tension $\left(\mathrm{kg} / \mathrm{cm}^{2}\right)$} \\
\cline { 2 - 4 } \multicolumn{1}{c}{ Animal age } & $\mathrm{ACh}$ & CCK-OP & Potassium \\
\hline Fetal $(n=16)$ & $0.16 \pm 0.02$ & $0.15 \pm 0.03$ & $1.0 \pm 0.02$ \\
Newborn $(n=13)$ & $0.25 \pm 0.03^{*}$ & $0.24 \pm 0.05^{*}$ & $0.21 \pm 0.02^{*}$ \\
Young adult $(n=12)$ & $0.50 \pm 0.05 \dagger$ & $0.54 \pm 0.10 \dagger$ & $0.54 \pm 0.05 \dagger$ \\
\hline
\end{tabular}

* Significantly different from fetal value.

$\uparrow$ Significantly different from newborn value.

Table 2. $p D_{2}{ }^{*}$ values for isolated strips of gallbladder smooth muscle as a function of developmental age (mean \pm SEM)

\begin{tabular}{lccc} 
& \multicolumn{3}{c}{ Agonist } \\
\cline { 2 - 4 } \multicolumn{1}{c}{ Animal age } & ACh & CCK-OP & Potassium \\
\hline Fetal $(n=16)$ & $5.46 \pm 0.34$ & $9.41 \pm 0.45$ & $1.92 \pm 0.38$ \\
Newborn $(n=13)$ & $5.89 \pm 0.26$ & $9.04 \pm 0.36$ & $2.10 \pm 0.31$ \\
Young adult $(n=12)$ & $6.11 \pm 0.30$ & $9.64 \pm 0.56$ & $1.87 \pm 0.32$ \\
\hline
\end{tabular}

* Negative logarithm of the dose of agonists which causes a one-half maximal response.

opmental age, no significant differences existed among the doseresponse curves with respect to their $\mathrm{pD}_{2}$ values (Table 2).

The data summarizing the effect of developmental age on the contractile response to CCK-OP are presented in Figure 2. Within each age group increasing the concentration of CCK-OP resulted in an increased force of contraction. Similar to the results observed with ACh stimulation, the maximal contractile response increased as a function of the age of the animal (Table $1)$. The sensitivity of the tissues for the agonist $\left(\mathrm{pD}_{2}\right.$ value) was independent of the developmental age (Table 2).

In order to determine whether the age-related increases in force development were the result of the development of receptor mediated processes, or whether development was associated with an overall increase in contractility, the tissues were examined for 


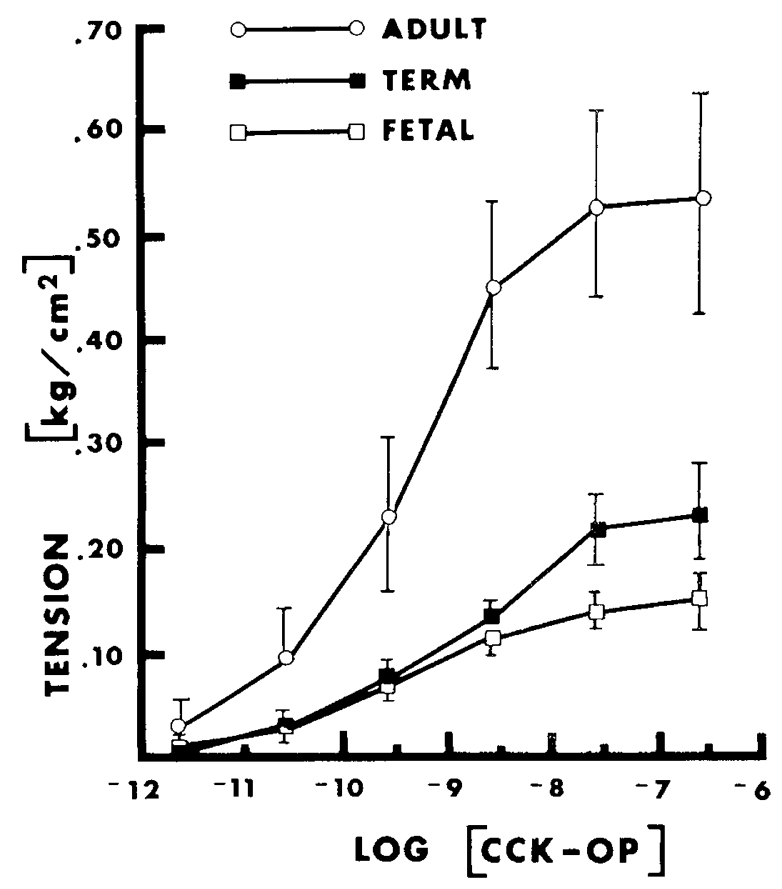

Fig. 2. Dose-response curve for CCK-OP in isolated gallbladder smooth muscle strips from fetal, newborn, and young adult guinea pigs. Each point represents the mean \pm SEM of at least 12 determinations.

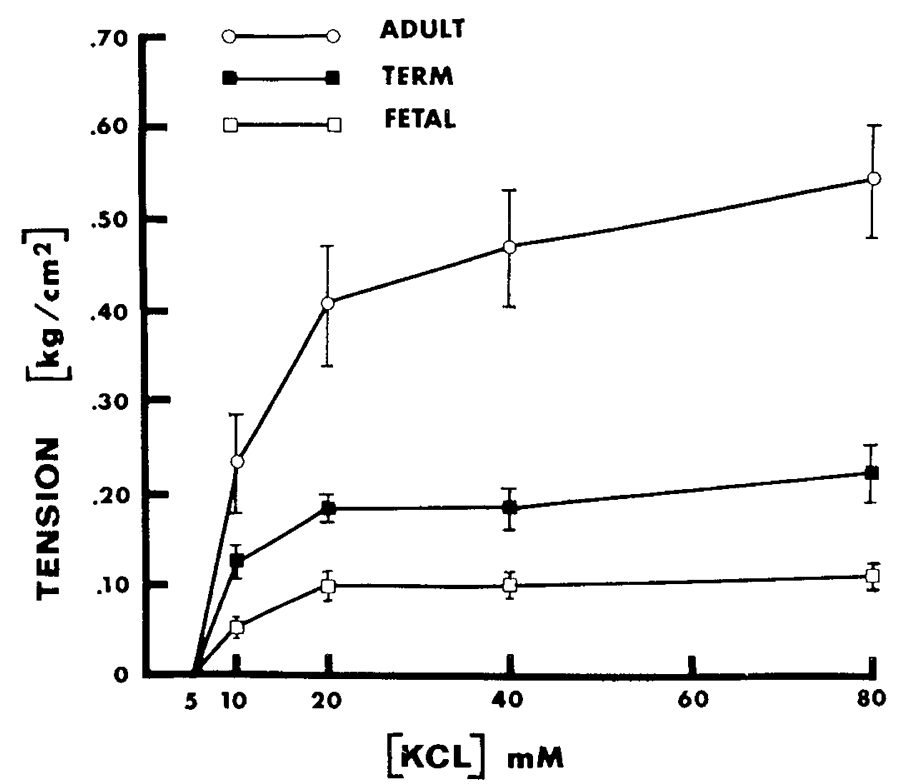

Fig. 3. Dose-response curve for potassium stimulation in isolated gallbladder smooth muscle strips from fetal, newborn, and young adult guinea pigs. Each point represents the mean \pm SEM of at least 12 determinations.

their contractile responsiveness to increased extracellular potassium. Potassium stimulation is thought to involve membrane depolarization and to be independent of any receptor mediated processes (14). Increasing the potassium concentration from normal levels $(5 \mathrm{mM})$ to $20 \mathrm{mM}$ resulted in progressively larger contractile responses in all tissues (Fig. 3). Increasing the potassium concentration above $20 \mathrm{mM}$ did not result in any further significant increases in the magnitude of the contractions. Analysis of the individual dose-response curves indicated that the $\mathrm{ED}_{50}$ (dose eliciting a one-half maximal response) was similar in all age groups (Table 2).
Within each age group the maximal forces generated in response to $\mathrm{ACh}, \mathrm{CCK}-\mathrm{OP}$, and potassium were not significantly different.

\section{DISCUSSION}

It is well established that the digestive and absorptive functions of the gastrointestinal tract continue to develop after birth (1-3). In contrast, relatively little information is available concerning the developmental characteristics of gastrointestinal motility. However, it has recently been reported (10) that the neonatal gallbladder develops a lower intraluminal pressure in response to agonist simulation than does that of the adult. The authors suggested that the reduced pressure may be related to a decreased smooth muscle contractility. The present study examined the relationship between contractility and developmental age using an isolated muscle strip preparation. Such an approach eliminates any extrinsic neural and hormonal influences which might modulate gallbladder motility in vivo and, therefore, provides a more accurate evaluation of contractility. The tissues were stimulated with agonists that are known to initiate gallbladder smooth muscle contraction by a direct effect on the muscle and that operate through different mechanisms to effect a contractile response (membrane receptor stimulation, $\mathrm{ACh}$, and $\mathrm{CCK}$; membrane depolarization, $\mathrm{K}+$ ). This approach permitted a more thorough assessment of the contractile process as a function of developmental age.

The results of the present study indicate that the guinea pig is a good animal model to study the developmental characteristics of gallbladder smooth muscle contractility. This is of interest when one considers that the guinea pig, unlike other animals normally used to evaluate the development of the hepatobiliary system such as the rat, is quite mature at birth and develops very rapidly. Nevertheless, age-related differences were observed with respect to the presence and coordination of spontaneous phasic contractions. Although regular rhythmic contractions were observed in young adults, tissues from newborn animals evidenced an erratic contractile pattern. Tissues from fetal guinea pigs rarely exhibited spontaneous phasic contractions. The underlying mechanism responsible for the phasic contractile activity of the gallbladder is unknown. In other gastrointestinal smooth muscles spontaneous contractions are the consequence of an underlying electrical signal, termed the electrical slow wave or basic electrical rhythm (15). The development of an action potential in conjunction with the slow wave results in a contraction. It has been reported for both the lamb and the dog that the frequency and coordination of these electrical signals in gastric and small intestinal smooth muscle continues to develop in the newborn animal $(16-18)$. Thus it is tempting to speculate that the progressive development in the frequency and regularity of spontaneous contractions in the guinea pig gallbladder reflects a maturation of the processes responsible for the generation of electrical slow waves.

ACh was capable of eliciting a contraction in all of the tissues studied, indicating that $\mathrm{ACh}$ receptors are present and functional prior to birth. Functional cholinergic receptors have been demonstrated in other gastrointestinal and nongastrointestinal smooth muscles from fetal animals (19-24). Analysis of the doseresponse relationship indicated that the concentration of agonist required to elicit a one-half maximal response did not change during development. In contrast, the absolute magnitude of the contractions increased as a function of developmental age. These findings are consistent with the developmental characteristics of the cholinergic receptor in other smooth muscles. Boreus and McMurphy (20) found that the maximal isometric tension which could be developed by segments of ileum from human fetuses increased 20 -fold during gestation. The force generating capacity of smooth muscle from the cat esophagus, stomach and small bowel, and rat stomach also has been shown to be directly related to the postnatal age of the animal (25-27). The reported increases 
in force development could not be accounted for solely on the basis of an increase in muscle mass, suggesting maturation of the factors which affect contractility. In the present study all contractile responses were normalized for tissue size. Thus it appears that gallbladder smooth muscle also is characterized by contractility changes during development and maturation.

The developmental characteristics of the contractile response to CCK-OP were virtually identical to the results obtained with ACh stimulation (increased force of contraction; no change in tissue sensitivity). It has recently been reported that $\mathrm{ACh}$ and CCK-OP each stimulate gallbladder contraction through a similar mechanism (11). It is conceivable that the present findings are the result of a maturation of this excitation-contraction coupling pathway and not the result of an overall increase in force generating ability. In order to test this possibility the muscle strips were stimulated with an agonist that activates muscle contraction by a process independent of receptor activation (potassium-induced membrane depolarization). As was observed with receptor-mediated agonist stimulation, the magnitude of the potassium-induced contractions increased with developmental age. This result would suggest that the increased force of contraction which is observed as the animal matures reflects an overall increase in the effectiveness of the contractile process, i.e., contractility.

In conclusion, studies were designed to characterize the development of gallbladder smooth muscle contractility using isolated muscle strips from fetal, newborn, and young adult guinea pigs. Contractions were elicited using neural (ACh) and hormonal (CCK-OP) agonists considered to be involved in the physiological regulation of gallbladder contraction. Each of these agonists initiates a contraction by the activation of membrane receptors. In addition, the tissues were stimulated via membrane depolarization (potassium). The data can be summarized as follows: 1) $\mathrm{ACh}$ and CCK-OP receptors are present and functional prior to birth;2) the sensitivity of gallbladder smooth muscle to ACh and CCK-OP stimulation is independent of the age of the animal; 3 ) the magnitude of the contractions increased with increasing developmental age. All contractions were normalized for tissue cross-sectional area; thus gallbladder smooth muscle from the guinea pig appears to be characterized by an increase in contractility as the animal develops from the neonate to the adult. However, because no attempt was made to quantify the number of the smooth muscle cells per unit cross-sectional area in any age group, it is not possible to assess the contribution of an increased muscle mass to the observed results. It is possible that the increased force development reflects both anatomical (muscle mass) and functional (contractility) changes. It is tempting to speculate that the observed results provide an additional explanation for the decreased choledochal bile flow seen in the neonate.

Acknowledgments. The authors acknowledge the fine secretarial assistance of Miriam Parker, Vern Ukkerd, and Beverly Yeager.

\section{REFERENCES}

1. Henning SJ 1981 Postnatal development: coordination of feeding, digestion, and metabolism. Am J Physiol 241:G199-G214

2. Aynsley-Green A 1983 Hormones and postnatal adaption to enteral nutrition. J Pediatr Gastroenteral Nutr 2:418-427

3. Grand RJ, Stutphen JL, Montgomery RK 1979 The immature intestine: implications for nutrition in the neonate. In: Development of Mammalian Absorptive Processes. Excerpta Medica, New York, pp 293-311 (Ciba Found Symp 70, New Ser)

4. Hamosh M 1981 Oral poses and lipid digestion during the neonatal period. In Lebenthal E (ed) Textbook of Gastroenterology and Nutrition in Infancy. Raven Press, New York, pp 445-463

5. Watkins JB, Ingall D, Szczepanik P, Klein PD, Lester R 1973 Bile-salt metabolism in the newborn. Measurement of pool size and synthesis by stable isotope technic. N Engl J Med 288:431-434

6. Balistreri WF 1981 Neonatal cholestasis. In: Lebenthal E (ed) Textbook of Gastroenterology and Nutrition in Infancy, Vol 2. Raven Press, New York, pp 1081-1108

7. Smallwood RA, Lester R, Piasecki GJ, Klein PD, Greco R, Jackson BT 1972 Fetal bile salt metabolism II. Hepatic excretion of endogenous bile salt and taurocholate load. J Clin Invest 51:1388-1397

8. Watkins JB, Szczepanik P, Gould JB, Klein P, Lester R 1975 Bile-salt metabolism in the human premature infant. Gastroenterology 69:706-713

9. Ryan JP 1981 Motility of the gallbladder and the biliary tree. In: Johnson LR (ed) Physiology of the Gastrointestinal Tract. Raven Press, New York, pp 473-493

10. Kaplan GS, Bhutani UK, Shaffer TH, Tran N, Koslo RJ, Wolfson MR 1984 Gallbladder mechanics in newborn piglets. Pediatr Res 18:1181-1184

11. Ryan JP 1984 Effect of pregnancy on gallbladder contractility in the guinea pig. Gastroenterology 87:674-678

12. Herlihy JT, Murphy RA 1973 Length-tension relationship of smooth muscle of the hog carotid artery. Circ Res 33:275-283

13. van Rossum JM 1963 Cumulative dose response curves II. Technique for the making of dose-response curves in isolated organs and the evaluation of drug parameters. Arch Int Pharmacodyn 143:299-230

14. Bolton TB 1979 Mechanisms of action of transmitters and other substances on smooth muscle. Physiol Rev 59:607-718

15. Szurszewski JH 1981 Electrical basis for gastrointestinal motility. In: Johnson LR (ed) Physiology of the Gastrointestinal Tract. Raven Press, New York, pp 1435-1466

16. Barbero GJ, Kim SC, Davis J 1985 Duodenal motiliby patterns in infants and children. Pediatrics 22:1054-1063

17. Bueno L, Ruckebusch $Y 1979$ Perinatal development of intestinal myoelectric activity in dogs and sheep. Am J Physiol 237:E61-E67

18. Morris FH, Spedale SB, Weisbrodt NM 1981 Development of small bowel motility in beagle puppies. Pediatr Res 15:486 (abstr).

19. Boreus LO 1968 Demonstration of a receptor reserve for acetylcholine in the human fetus. Acta Physiol Scand 72:194-199

20. Boreus LO, McMurphy DM 1971 Ontogenic development of cholenergic receptor function in the guinea pig ileum. Acta Physiol Scand 81:143--144

21. Mayazaki H, Ohga A, Saito K 1982 Development of motor response to intramural nerve stimulation and to drugs in rat small intestine. B J Pharmacol 76:531-540

22. Hayashi S, Toda N 1980 Age-related alterations in the response of rabbit tracheal smooth muscle to agents. J Pharmacol Exp Ther 214:675-68

23. Seidel CL, Allen JC 1979 Pharmacologic characteristics and actomyosin content of aorta from neonatal rats. Am J Physiol 237:C81-C86

24. Stage DM, Ljung B 1978 Neuroeffector maturity of portal veins from newborn rats, rabbits, cats and guinea pigs. Acta Physiol Scand 102:218-223

25. Hillmeier C, Gryboski J, McCallum R, Biancani P 1981 Contractility of the developing LES in the kitten. Pediatr Res 15:534 (abstr)

26. Hillimeier C, Gryboski J, McCallum R, Biancani P 1982 Differential development of the cat's upper intestinal tract. Pediatr Res 16:112 (Abstr)

27. Yoshida N, Taniyama K, Tanaka C 1979 Adrenergic innervation and cyclic adenosine $3^{\prime}, 5^{\prime}$ monophosphate levels in response to nonepinephrine in stomach of postnatal rats. J Pharmacol Exp Ther 211:174-180 